\title{
The Learning Zone in New Product Development
}

\author{
Anna Shaojie Cui ${ }^{1}$ \\ University of Illinois at Chicago \\ Kwong Chan \\ University of Massachusetts at Amherst \\ Roger J. Calantone \\ Michigan State University
}

*Accepted for publication for IEEE Transactions on Engineering Management

${ }^{1}$ Corresponding author: Anna Shaojie Cui, Assistant Professor of Marketing, College of Business Administration, University of Illinois at Chicago, University Hall 2223, $601 \mathrm{~S}$. Morgan Street, Chicago IL 60607, USA. Tel: 001-312-996-7326. Fax: 001-312-996-3559. Email: ascui@uic.edu. 


\title{
The Learning Zone in New Product Development
}

Keywords: information, innovation, knowledge, organizational learning, new product development

\begin{abstract}
New information is the fuel that allows organizations to innovate. Yet the generation of new information may yield little benefit if existing practices prevent the firm from integrating new insights effectively. This study provides evidence that existing knowledge has both an enhancement effect that improves the firm's ability to benefit from new information, and an inhibition effect that lowers its motivation to learn. Firms that utilize a moderate level of existing knowledge benefit from new information more than firms that rely too little or too much upon existing knowledge. We call this optimal circumstance the "learning zone". Furthermore, we find that the moderating effects of existing knowledge are stronger for new products of lower novelty that provide a similar learning context. In addition, as novelty increases, the prominence of the enhancement effect increases, whereas the inhibition effect becomes less prevalent. Highly novel products that are able to utilize existing knowledge are therefore most likely to benefit from new information. Existing technical knowledge is also found to inhibit the use of new information to a greater degree than market knowledge. The findings suggest that organizations should evaluate their reliance on existing knowledge and create a learning zone that provides the best condition for innovation.
\end{abstract}




\section{Introduction}

As competitive pressure and environmental complexity increase, the amount of data companies collect "has turned from a rain shower into a deluge" [1]. In developing new products, firms endeavor to understand customers' needs and potential market response. In the technical domain, the advancement in technology allows engineers and scientists to generate an unprecedented amount of technical data [2], [3]. However, these costly activities to generate market and technical information often fail to fulfill their promise [4], [5]. Attempts to be market responsive often lead to unexpected consequences [6], and gathering customer information has been found to have negative or no impact upon innovation outcomes and firm performance (e.g., [7], [8]). This phenomenon of unfulfilled promise is mirrored in engineering and $R \& D$ where a large amount of technical information may also be difficult to understand or integrate to improve product design [9]. Given the resource intensive nature of new information generation, the prevalence of such findings is worrying. Knowing when new information is likely to be beneficial would enable more efficient allocation of resources [10] and help firms more effectively learn. It is thus critical for a firm to understand when it is most able to benefit from new information, i.e., to be able to answer the question "When is my firm most able to learn?"

Part of the answer lies in the way a firm's existing knowledge is utilized in innovation projects. The new information a firm gathers needs to be combined with existing knowledge to improve new products. However, this integration process is more than a simple linear summation of old and new insights [10], [11], as the very acts of information search, interpretation and integration occur through the lens of existing understanding [10]. Existing knowledge influences how new information is interpreted, the extent to which it is integrated with existing systems and whether it is successfully utilized. Thus the ability to realize the benefit of new information is inevitably influenced by existing knowledge. 
While existing knowledge can enhance a firm's ability to understand and integrate new information [12], it may also create core rigidities [13] and competency traps [14] that inhibit the use of new information. Thus existing knowledge has both an enhancement effect, where a firm is more able to utilize new information when it is equipped with existing knowledge, and an inhibition effect where heavy reliance on existing knowledge increases the firm's attachment to existing routines and reduces its motivation to use new information. Such contrasting effects indicate a complex influence of existing knowledge upon learning. Although qualitative accounts of contrasting learning effects have captured the imagination of scholars, with Leonard-Barton's [13] account of core capabilities and core rigidities perhaps being the most salient, empirical tests remain sparse. Studies that simultaneously consider enhancement and inhibition effects, to the best of our knowledge, are absent. A few simulation studies have shown existing competencies can impede learning [15], although they only serve to highlight the paucity of empirical work.

Research concerning organizational memory finds that existing knowledge has differential effects upon innovation outcomes such as profitability and innovativeness [16] and that its effects vary according to environmental conditions [17]. However, these studies focus on the direct effects of existing knowledge upon innovation outcomes rather than the innovation process. Without exploring the learning process, that is, how existing knowledge may influence the use of new information to achieve outcomes, it is difficult to determine the reason for these diverse effects. Research in new product development has also emphasized the direct effects of either new information (e.g., [18], [19]) or existing knowledge (e.g., [17], [20]) on product outcomes, but has rarely examined how existing knowledge may influence the use of new information. Thus extant research does not reflect how new information is integrated and used in the product development process, and is at odds with learning theories that suggest new information is used through the lens of existing knowledge. 
This study examines how existing knowledge influences a firm's ability to learn from new information in the context of new product development. We propose that a moderate level of existing knowledge provides the best condition for learning. We further examine how such a curvilinear effect is moderated by the novelty of the innovation context. The findings provide empirical evidence for the enhancement and inhibition effects of existing knowledge upon learning, and allow for the identification of an optimal learning zone where new information is most beneficial for innovation.

\section{Theory and hypotheses}

New product development (NPD) is an ideal context for this study because it is an organizational activity that combines new information generated via search and experimentation with existing routines and competences [21]. It is suitable for examining the interplay between new information and existing knowledge in the learning process. To measure the ultimate effect of this interplay, we use new product advantage as the focal outcome. New product advantage is defined as the extent to which a product is superior to market alternatives, that is, it provides unique benefits and thus better meets customers' needs [22]. New product advantage is the direct outcome of integrating new information and existing knowledge, thus a more suitable performance measure than profitability or market share, which can be achieved in ways that do not depend upon the integration of new information and existing knowledge (such as through promotion programs or cost reduction).

\section{A. Learning as manifest change: the effect of new information generation on new product} advantage

To examine the benefit of new information, we define learning as manifest change resulting from the use of new information ${ }^{2}$. In the context of NPD, learning occurs if new

\footnotetext{
${ }^{2}$ Some research uses the concept of learning more broadly and considers information generation that increases the range of potential actions but does not lead to actual actions also as learning [11]. We argue that manifest change is necessary for
} 
information generation leads to observable change in new product outcomes. Thus we view learning as productive use of new information. Specifically in our regression analyses, new product advantage is the dependent variable and the effect of new information generation upon new product advantage indicates learning, that is, how effectively the firm turns new information into output.

We consider new information generation in market and technical areas because they represent crucial competence areas in NPD. During the NPD process, marketing research activities, such as screening of product ideas, preliminary market assessment, detailed market studies and pre-commercial business analysis, enable the firm to generate new market information that informs a product's feature design, target market and positioning [23]. New technical information is generated through activities such as technical assessment, development of product prototypes, and product testing [9], [23], [24]. Technical information gathered through these processes helps the firm understand design feasibility, technological requirements and performance specifications for product features.

Research findings concerning the effect of new information on product outcomes are inconsistent. Some research finds that market information generated through detailed market studies enables the development of advantageous products (e.g., [22], [25]), whereas other studies indicate that relying on customer information may reduce or have no effect upon innovation performance (e.g., [4], [7], [8]). Information generated through technical activities has been found to enhance feature design [26], but such information may not be easily understood or integrated to generate superior products [9]. These inconsistent findings suggest that the effect of new information on new product advantage may be dependent upon certain conditions. We propose that the level of existing knowledge involved in a NPD

learning since new information that does not lead to improved product outcomes consumes resources and creates inefficiency. Our approach captures the actual benefit of new information. It also provides a better way to assess learning, because it is difficult to measure an organization's potential actions. 
project is a condition that determines whether new information can be effectively used to generate superior products.

\section{B. The moderating impact of existing knowledge}

We define existing knowledge as the degree to which a NPD project relies on the firm's existing market and technical systems. If a new product project uses existing distribution channels or resources, and faces familiar customers and competitors, then it utilizes a high level of existing market knowledge. Similarly, projects that use existing technologies and manufacturing processes rely on high levels of existing technical knowledge. On the other hand, if a NPD project requires substantial changes to existing systems, its reliance on existing knowledge is low.

Both new information and existing knowledge are important inputs to the NPD process where they are combined to generate product solutions. The amount of existing knowledge that a NPD project utilizes can influence the degree to which new information is understood, whether it can be effectively combined with existing knowledge, and whether it is successfully utilized in product design.

Prior knowledge helps distinguish between relevant and irrelevant external information [27] as well as interpret relevant information [10], [28]. Similarly, for internally generated information such as that obtained from experiments, insights are also of higher quality when informed by past experience [14]. In NPD, market information is often generated externally through customer research, and technical information is often generated through internal experimentation such as in-house testing, but in either case the interpretation of new information is enhanced when managers are equipped with existing knowledge [18].

Furthermore, existing knowledge improves the utilization of new information to generate superior products. Research suggests that innovation is achieved through recombination of components of prior and/or new knowledge [29], [30]. The greater a firm's 
existing knowledge, the more likely it can identify effective ways of combining new information and existing knowledge to generate feasible and advantageous product solutions [31], [32]. Firms with higher levels of existing knowledge also have experience with a wider variety of knowledge components, and thus are able to more effectively select appropriate combinations for use in NPD [29]. On the other hand, lower knowledge stocks will limit the possibility of successful combination.

The previous arguments focus upon the firm's ability to learn, which is distinct from the motivation to learn. While existing knowledge improves a firm's capacity to better utilize new information, when the firm heavily relies on existing knowledge, its motivation to use new information tends to reduce as it becomes more attached to existing routines and less open to new information ${ }^{3}$.

Managers tend to value familiar routines [14] and avoid ambiguity and risks [33]. Over reliance on existing technology or marketing systems increases managers' confidence in their knowledge base, which may lead them to resist the use of new information. Such resistance arises in multiple ways including: reframing new issues in a more familiar way that oversimplifies the problem [34], applying more stringent quality criteria for new information, and expressing distrust toward individuals who provide new information [33]. Such behaviors often happen unconsciously. Managers may not be aware of the biases created by their prior understandings, but the common end result is that new information inconsistent with past understandings is ignored or misinterpreted [10].

\footnotetext{
${ }^{3}$ Our discussion on learning motivation focuses on the openness to absorb and use new information, not the willingness to generate new information, because this study is interested in the productive use or benefit of new information. While existing knowledge may influence the firm's motivation to collect new information, our focus is on how the benefit of newly generated information may vary depending on the levels of existing knowledge. As a supplementary analysis we examined the correlation between existing knowledge and new information generation in our dataset but did not find any significant relationship (Further detail is included in the discussion section). We also followed the procedure proposed by Baron and Kenny [35] to test whether new information generation mediates the relationship between existing knowledge and new product advantage, but did not find any significant mediation effects.
} 
Furthermore, existing knowledge is associated with different organizational members. Established senior members often derive authority from exclusive access to existing knowledge [36] and association with dominant disciplines [13]. When a new product does not utilize substantial existing knowledge, the project is more likely to break free from the influence of established disciplines [37]. In contrast, heavy reliance upon existing knowledge can lead to undue influence from established functional areas that impedes consideration of divergent ideas provided by other functions [38], 39]. Thus the dominance of established disciplines stifles heterogeneity of skillsets utilized in NPD, which reduces the number of possible knowledge combinations and limit the potential and quality of innovation [40], [41]. Therefore high reliance on existing knowledge can create "learning traps" [14] that impede innovation. The overall propensity for existing practices to inhibit the use of new information has been shown in both case [13] and simulation studies [15].

The benefit of new information is therefore dependent upon the level of reliance on existing knowledge. At low levels of existing knowledge, the firm lacks the competence to learn and is less able to benefit from new information. At higher levels of existing knowledge, the firm's learning competence is enhanced; however, excessive reliance on existing knowledge reduces its motivation to learn. The negative motivational effects may be so strong that they render learning competence ineffective because organizational members are unwilling to pursue learning. Collectively, this suggests a curvilinear effect where moderate levels of existing knowledge are most beneficial for learning. At this intermediate condition, learning enabled by existing knowledge has yet to be overcome by the negative motivational influence, and the firm is able to learn most effectively. Thus we hypothesize: H1a: The effect of new market information generation upon new product advantage is moderated by existing market knowledge in an inverse U-shaped manner where 
existing market knowledge first enhances then inhibits the effect of new market information generation.

H1b: The effect of new technical information generation upon new product advantage is moderated by existing technical knowledge in an inverse U-shaped manner where existing technical knowledge first enhances then inhibits the effect of new technical information generation.

\section{The role of novelty}

The field of organizational learning emphasizes the role of contextual similarity between past and present tasks [12], [34]. A NPD project is a learning context where existing knowledge is applied and combined with new information to generate a new product. This learning context may be similar to or different from previous circumstances in which existing knowledge was applied. The level of dissimilarity of the NPD learning context can be represented by the degree of innovativeness of the new product ${ }^{4}$. When a product is very new, it may still utilize existing technology or marketing systems, but existing knowledge is applied in a way that is substantially different from prior practice. Thus novelty is the overall newness of a product that represents difference in the context in which market and technical knowledge is applied. We argue that novelty of the learning context influences the extent to which existing knowledge can impact the use of new information. Specifically, we propose that the curvilinear moderation effect of existing knowledge upon the relationship between new information and new product advantage is weaker for highly novel products.

\footnotetext{
${ }^{4}$ While product innovativeness may be argued to be a NPD outcome, here we treat it as a contextual factor because the overall newness of the product is often set at a certain level at the start of a NPD project. This approach has been used in previous studies [20]. In addition, new product innovativeness and new product advantage are distinct concepts [42]. Innovativeness is concerned with the overall newness of a product, whereas product advantage refers to a product's superiority relative to other products in the marketplace. While a newer product tends to provide more advantages, newness also lowers customer familiarity and requires customer behavioral change, thus a newer product may not always be more advantageous, as customers tend to resist the adoption of unfamiliar products [43].
} 
New information is easier to understand when a firm has previously conducted activities in a similar context [12], [34]. The more divergent the context between current and previous learning situations, the less likely existing knowledge is able to facilitate the interpretation and use of new information, because previous knowledge combinations are less likely to be applicable. Even though a larger amount of existing knowledge provides more possible combinations, the new context of application limits the firm's ability to utilize them successfully. Therefore, the enhancement effect of existing knowledge is lower for highly novel products, that is, as the firm's reliance on existing knowledge increases, its ability to benefit from new information does not increase as sharply compared to when novelty is low.

The negative motivational effect of existing knowledge is also weaker for distal learning contexts. For projects in a similar domain, managers are more likely to rely on standard routines, leading to greater resistance to the use of new information. In contrast, when new projects are very novel, organizational members tend to be more open to new ideas as existing routines do not compete directly in the new context [13]. Lower applicability of existing knowledge in the new learning context also means dominant disciplines associated with existing knowledge are less influential, thereby permitting a diversity of knowledge to be used in product development. Thus when the level of existing knowledge is high, the novel context of a NPD project helps the firm break free from the negative motivational influence of existing knowledge. Therefore, as the firm's reliance on existing knowledge increases, its negative impact upon the use of new information does not increase as sharply compared to when novelty is low. This mitigated inhibition effect together with the previously discussed lesser enhancement effect leads us to hypothesize an overall weaker moderation effect of existing knowledge for higher levels of product novelty.

H2a: The curvilinear moderation of existing market knowledge upon the effect of new market information generation is weaker when product novelty is high. 
$\mathrm{H} 2 \mathrm{~b}$ : The curvilinear moderation of existing technical knowledge upon the effect of new technical information generation is weaker when product novelty is high.

III. Method

\section{A. Sample and data}

The sampling frame was obtained from a commercially supplied list covering the chemical, biochemical and pharmaceutical industries in North America. We randomly selected 700 firms from the list to contact. The questionnaire was administered by a professional survey research organization that conducted multiple callbacks. Incentives including a monetary amount and a copy of aggregated results were given to boost response. Preliminary research such as interviews and pretest of the questionnaire was conducted to ensure the quality of data collection. We received 451 usable responses, yielding a response rate of $64.4 \%$. The respondents were product line managers, new product development managers and product managers. Their primary functional areas in the company are distributed between marketing (42.6\%) and R\&D (35.9\%) and other areas such as production and general management $(21.5 \%)$. They were asked to answer the questions with regard to a recent new product project he/she worked on. Responding firms were diverse in scope. The number of employees ranged from 11 to 30,000 with an average of 1309 , while annual R\&D as a percentage of revenue ranged from $0.1 \%$ to $15 \%$ and averaged $3.8 \%$ of revenue. We used t-tests to compare early and late respondents. No significant differences were found for the key variables, suggesting non-response bias is not a significant problem [44].

\section{B. Measures}

Moorman and Miner's [16] measures of memory have been commonly used to measure knowledge (e.g. [17], [20]). A limitation of this approach is that self-reported levels of knowledge are based upon organizational awareness of knowledge, which, even if accurate, is insufficient to determine if the knowledge can be utilized in a learning task. We 
apply an action-based approach to measuring existing knowledge. The action-oriented perspective of knowledge [45] argues that the performance of a routine is a stronger indication that knowledge exists. Firms engaged in an activity necessarily have the requisite knowledge to perform that activity. Thus knowledge can be measured by the activities undertaken by a firm. If a NPD project utilizes existing marketing or technical systems, such activities are an indication of its reliance on existing knowledge.

Existing market knowledge: In measuring existing market knowledge, we assess the degree to which past distribution systems carry over to the current NPD project, and the degree to which the new product faces familiar customers and competitors. The items are borrowed from Cooper and Kleinschmidt [46] and Danneels and Kleinschmidt [47].

Existing technical knowledge: Existing technical knowledge is measured with the degree to which the technology used for the new product is found within the firm, and the extent to which existing manufacturing processes can be applied to the new product. The items are borrowed from Cooper and Kleinschmidt [46] and Danneels and Kleinschmidt [47].

New market information generation: We operationalize new market information generation as activities in the NPD process that are used to gather new market information. Specifically, we measure new product activities including screening of the product idea, preliminary market assessment, pre-commercial business analysis and detailed market studies. The degree to which these activities are carried out indicates the firm's effort to obtain new market formation related to the new product. The items are adapted from Cooper and Kleinschmidt [46] and Calantone, Schmidt and Song [48].

New technical information generation: We measure new product activities that are used to generate technical information, including preliminary technical assessment, development of a product prototype and in-house product testing. The items are adapted from Cooper and Kleinschmidt [46] and Calantone, Schmidt and Song [48]. Our measurement of 
market and technical information generation at several different phases reflects normative models of the NPD process [49].

The measures of new information generation are consistent with our action-based approach of measurement. They provide a means to assess ongoing activities of the firm rather than self-reported newness of information content, which tends to be more subjective. While existing knowledge measures the overall degree to which a NPD project relies on existing systems, the measures of new information generation are based upon specific information generation activities in the NPD process. This distinction allows us to clearly separate the measurement of new information and existing knowledge.

New product advantage: New product advantage measures the extent to which a new product is superior to competing products in terms of meeting customer needs, provides unique attributes that are not available from competing products, and offers highly visible benefits to the customers. The items are borrowed from existing research [50], [51].

Novelty: We assess novelty via product innovativeness. This measure rates the overall degree of innovativeness of the new product relative to other products in the market. This item is adapted from Atuahene-Gima [51] and Kleinschmidt and Cooper [42].

We conducted a confirmatory factor analysis (CFA) to assess measurement validity (see Appendix). The $\chi^{2}$ for the CFA model is 313.82 with 78 degrees of freedom. The fit indices are: comparative fit index (CFI) 0.91 , root mean square error of approximation (RMSEA) 0.082, which collectively indicate the measurement model has satisfactory fit. All item loadings are high $(\lambda>0.58)$ and significant $(t>11.00)$, providing evidence for convergent validity. Discriminant validity was assessed by examining pairs of constructs in a series of two-factor CFAs. Significant $\chi^{2}$ difference tests for each comparison indicated sufficient discriminant validity between the constructs [52]. 
To alleviate the concerns for potential common method bias, we first conducted Harman's one-factor test. Significantly worse fit for the one-factor model $\left(\chi^{2}=1748.80, \mathrm{df}=\right.$ 79) provides preliminary evidence that common method bias is not a threat to measurement validity. Second, we followed Lindell and Whitney's [53] approach to examine the influence of common method variance on the relationships among constructs. We selected market attractiveness, measured with economic climate and the number of profitable customers and innovative users in the market, as the marker variable because it is uncorrelated with new product advantage ( $\mathrm{r}=0.01$, not significant) [53]. We examined the correlations between market attractiveness and other constructs, and used the smallest correlation to partial out the influence of common method variance. The correlations among constructs did not substantially change and their significance remained the same, suggesting that the relationships among constructs are not accounted for by common method variance. Further, we utilized a structural equation model to examine the impact of common method variance on the relationships among constructs [54]. We used market attractiveness to identify a common method factor, on which the indicators of all constructs were loaded. Due to the difficulty of handling high order interactions in structural equation models [55], we only included main effects in the model. We compared coefficient estimates in models with and without the common method factor. The significance of the independent constructs stayed the same when the common method factor was included. For the significant paths, the difference between standardized coefficients averaged 0.004 , which is less than $2 \%$ of the original coefficients. These results indicate that common method variance does not seriously bias the relationships among constructs [53].

\section{Control variables}

We included a number of control variables. At the project level, we controlled for the use of cross-functional teams because teams have been found to improve new product 
performance [56]. With regard to firm characteristics, we controlled for firm size [57] and R\&D intensity [58]. Because environmental factors are known to impact new product success, we controlled for the firm's order of market entry [59], stage of product life cycle of the market entered [60] and increase in market competition [22]. Among the control variables, increase in market competition and cross-functional teams are self-report scales. For these two constructs, we conducted a CFA to assess measurement validity. The CFA model showed good fit $\left(\chi^{2}=17.41 / \mathrm{df}=5 ; \mathrm{CFI}=0.99 ;\right.$ SRMR $=0.034 ;$ RMSEA $\left.=0.074\right)$, with all item-construct loadings high $(\lambda>0.58)$ and significant $(t>11.77)$.

IV. Results

We used averaged scores for each construct and tested the hypotheses using OLS regression. All variables were mean-centered before analysis [61]. The interaction terms were added to the model sequentially (Table 2). F-tests indicated each step significantly improved model fit, providing support for the interaction model. To reduce the chance that higher order simple effects could be mistaken for interaction effects, we included quadratic effects for new market and technical information generation and found the results to be the same. We therefore omitted the quadratic terms to maintain a more parsimonious model. The variance inflation factors for all models were below the suggested cutoff value of 10 [62], indicating multicollinearity is not a serious concern. Hypothesis testing is based upon Model 4 that exhibits the most explanatory value.

$<<$ Insert Tables 1 and 2 here $>>$

\section{A. The impact of existing knowledge upon learning}

Given that learning in our analysis is represented by the effect of new information generation upon new product advantage, the impact of existing knowledge upon learning is reflected in the interaction terms between new information generation and existing knowledge. The curvilinear moderation effects of existing knowledge are tested with the 
quadratic interaction terms between new information generation and existing knowledge. The quadratic interactions are significant and negative for both market $(\beta=-0.03, p<0.01)$ and technical dimensions $(\beta=-0.02, \mathrm{p}=0.01)$, indicating an inverse $\mathrm{U}$-shaped relationship. $\mathrm{H} 1$ is supported. The linear interaction terms are also negative and significant for market $(\beta=-0.07$, $\mathrm{p}=0.01)$ and technical domains $(\beta=-0.12, \mathrm{p}<0.01)$. Note that when quadratic interaction terms are included, it is the signs of the quadratic interaction terms that determine the shape of the curve -- U-shaped or inverse U-shaped [61]. In such models, the linear interaction terms determine the relative position of the curve along the axis rather than the shape of the curve, and they cannot be interpreted independent of the quadratic interaction terms.

We graph these effects in Figure 1 where the Y-axis is the effect of new information generation on new product advantage and represents learning. For both market and technical areas, existing knowledge is shown to first enhance and then inhibit learning. The contribution of new information generation to new product advantage is the highest at a moderate level of exiting knowledge ${ }^{5}$.

\section{B. The role of novelty}

$<$ Insert Figure 1 here $>>$

To examine the role of novelty in influencing the impact of existing knowledge upon learning, we included interactions of novelty with the independent variables. The results

\footnotetext{
${ }^{5}$ Prior knowledge may also influence the use of new information through a substitution effect as firms may have a finite need for insight and seek information only to the degree that existing knowledge is insufficient [63]. The implication is that if new information does not appear to be beneficial, it could be because the organization does not need the new information. An examination of the regression results in Model 2 of Table 2 shows negative linear interactions between new information generation and existing knowledge, indicating the existence of substitution effects. However, such substitution effects do not completely explain the relationship between new information generation and existing knowledge. In better specified Model 3 and Model 4, the significant curvilinear interactions between new information generation and existing knowledge indicate that, in addition to reducing the need for new information, existing knowledge influences the use of information through the competence and motivational effects discussed in this study. Since the motivational inhibition effect occurs at high levels of existing knowledge, learning effects suggest a curvilinear interaction between new information generation and existing knowledge, while substitution effects manifest as a monotonic negative relationship. Thus the observed curvilinear interactions are valid evidence for the proposed learning effects. Model 2 that represents only substitution effects is a mis-specified model compared to Model 3 and Model 4 that correctly capture the effects of existing knowledge.
} 
show that novelty moderates $(\beta=0.01, \mathrm{p}<0.01)$ the quadratic impact of existing market knowledge upon the benefit of new market information generation. Given the negative quadratic interaction between new market information generation and existing market knowledge, these positive coefficients indicate that increased product novelty reduces the strength of the interaction between existing market knowledge and new market information generation, providing support for $\mathrm{H} 2 \mathrm{a}$. Specifically, this indicates that novelty changes the shape of the inverse U-shaped curve. High novelty results in flatter curves as existing knowledge becomes less relevant (and therefore impacts the use of new information less) in dissimilar learning contexts. Novelty does not significantly influence the quadratic moderating impact of existing technical knowledge $(\beta=0.001, p=0.81)$. H2b is not supported. However, novelty significantly influences the linear moderating impact of existing technical knowledge $(\beta=0.02, p=0.01)$. This indicates that novelty does not change the shape (steepness) of the inverse U-shaped curve for technical knowledge, but rather changes the position of the curve along the axis.

$<<$ Insert Figure 2 here $>>$

Figure 2 shows the moderation effects of existing knowledge under different levels of novelty. The three lines correspond to average, high, and low (one standard deviation above and below the mean respectively) levels of novelty. Consistent with $\mathrm{H} 2 \mathrm{a}$, the graph for market activities shows that low novelty has the steepest inverse U-shaped curve, indicating the strongest effect of existing knowledge in influencing the benefit of new information. The effect is similar but less pronounced for products at the mean value of novelty. Interestingly, for highly novel products, existing market knowledge is monotonically beneficial for the use of new information, although this effect is one of mitigated loss as the effect of market information generation is mostly negative (negative $\mathrm{Y}$ values occur for most of the $\mathrm{X}$-axis range for high novelty). 
The graph for technical activities at high novelty indicates that existing knowledge first enhances and then inhibits the use of new information, supporting the hypothesized effects. However, as product novelty decreases, the range of $\mathrm{X}$-values for which existing technical knowledge exhibits enhancing effects decreases. When product novelty is low, existing technical knowledge exhibits mainly an inhibition effect upon the use of new information. Thus when compared to market knowledge, reliance upon technical knowledge has a greater capacity to inhibit learning.

\section{Discussion}

This study examines the impact of existing knowledge upon the firm's ability to learn from new information. It finds that existing knowledge initially enhances learning, but when the reliance on existing knowledge increases to a high level, it shows an inhibition effect upon learning. This finding suggests that there is an optimal "learning zone" characterized by a moderate level of existing knowledge where firms are best equipped to learn. Furthermore, the moderation effects of existing knowledge are found to be stronger for innovations of lower novelty, suggesting that the role of existing knowledge is influenced by the similarity of the current learning context compared to prior applications. In addition, differential effects are found across market and technical disciplines. The findings suggest that the benefit of new information can only be understood conditional upon the level of existing knowledge.

\section{A. The curvilinear impact of existing knowledge}

Despite qualitative accounts of enhancement and inhibition influences of existing knowledge upon learning, empirical tests remain sparse. Studies that simultaneously consider enhancement and inhibition effects are absent. This study not only provides the first empirical test for the contrasting effects of existing knowledge, but also demonstrates that the very same knowledge that assists learning can also inhibit learning. Future research should consider curvilinear models to capture the influence of prior knowledge. 
Prior research has found that existing knowledge has direct effects on new product outcomes such as profitability and innovativeness. Our results show that the impact of existing knowledge has another key dimension based upon its influence on the use of new information. A better understanding of the impact of existing knowledge upon the learning process may help to explain the differential direct effects of existing knowledge upon different outcomes and under different environmental conditions [16], [17].

The curvilinear effect of existing knowledge suggests the need to evaluate the reliance on existing knowledge when acquiring new information. When existing knowledge is limited, the firm may not be able to understand new information or generate sufficient knowledge combinations to successfully use new information. On the other hand, with high levels of existing knowledge, new information may not be effectively used due to interpretation bias caused by ingrained practices or resistance from organizational members associated with existing systems. Given the resource intensive nature of information generation activities, information generation should be avoided unless (1) the firm is equipped with sufficient knowledge to integrate new information and (2) organizational resistance can be appropriately overcome. Instead of applying standard processes of information generation to all NPD projects, firms need to evaluate existing systems and adjust information generation activities accordingly. While prior work has found that rigid NPD routines can restrict learning and hurt product performance [64], an inspection of Table 1 shows no significant correlation between new information generation and existing knowledge, indicating that firms do not systematically adjust their information generation activities. This suggests possible inefficiencies and highlights the importance of considering the role of existing knowledge in learning.

B. The role of novelty 
We find that existing knowledge has a stronger influence upon learning for less novel products. This finding suggests that the learning context in which knowledge is applied influences the enhancement and inhibition effects of existing knowledge. While the literature has often intertwined knowledge context and quantity, we find distinct effects for the context in which learning occurs and the quantity of existing knowledge utilized.

An interesting finding is that, although the application of existing knowledge may be more difficult for a highly novel product, the use of existing knowledge is more likely to be beneficial in such contexts. As shown in Figure 2, when product novelty increases, the prominence of the enhancement effect increases, whereas the inhibition effect becomes less prevalent. For the market domain, the inhibition effect of existing knowledge is only present at low and moderate levels of novelty; at high levels of novelty, existing market knowledge monotonically enhances the use of new information. In the technical domain, primarily negative effects of existing knowledge are observed for low and moderate novelty, while a large range of positive effect is present for products of high novelty. Thus a highly novel product that is able to utilize existing systems is most likely to benefit from new information. Firms that are able to find ways to recombine knowledge in new innovation contexts are more likely to be successful innovators.

The greatest benefit of new information is achieved when the product is of low novelty (Figure 2), suggesting that new information generation is generally more beneficial for less novel products. When firms move to unfamiliar contexts, the difficulty of using new information is substantially increased, as previous knowledge combinations are less applicable. This finding highlights the challenge of radical innovation and is consistent with the scarcity of successful radical innovations in the market [65].

Differential effects are found across market and technical domains. First, existing technical knowledge shows more inhibition effects than market knowledge. For low and 
moderately novel products, while existing market knowledge shows both enhancing and inhibition effects, existing technical knowledge mainly inhibits learning. For highly novel products, existing market knowledge mainly enhances learning, although technical knowledge can both enhance and inhibit the use of new information. Being embedded in technological systems, manufacturing facilities and experts with specialized training, technical knowledge is highly context-dependent and difficult to communicate [32], [66]. The sticky nature of technical knowledge may create greater rigidity than market knowledge [67].

Although the greatest benefit of new market and technical information is both achieved at low novelty, due to the stronger rigidity in technical knowledge, this happens at low (rather than medium) levels of existing knowledge for the technical domain (Figure 2). For products of low novelty, technical rigidity is even stronger due to context similarity. Using a lower amount of existing knowledge in the project helps to avoid the negative consequences of such rigidity. Thus a combination of low novelty and low existing knowledge provides a learning context where existing knowledge is applicable but does not create too much inhibition effect. Such a scenario produces higher returns than acquiring new information at high novelty, where existing knowledge is difficult to apply yet the negative effects of learning traps can be strong due to the high rigidity in technical knowledge.

Second, for highly novel products, while technical learning follows the hypothesized inverse U-shaped curve, existing market knowledge monotonically improves the use of new market information. This positive influence is through mitigating the negative effect of market information generation upon product advantage (negative $\mathrm{Y}$ values for high novelty) (Figure 2). Prior research has argued that strong reliance on customer information may limit creativity because customers tend to rely on past experience and focus on specific product features and preferences, but lack the ability to conceive of future needs, which is crucial for highly novel products [68], [69]. Our finding supports these arguments. Gathering too much 
market information may reduce focus in the NPD process and constrain the success of highly novel products. Importantly, existing market knowledge is able to mitigate the negative influence of new market information for highly novel products. When the firm has a strong understanding of the market, it is more able to translate specific customer inputs into fundamental customer needs, which are more likely to lead to broad exploration [68]. Therefore, for highly novel products, the positive role of existing market knowledge is enhanced due to the increased need to correctly interpret customer information, whereas the inhibition impact is mitigated due to the new learning context. The result is a beneficial effect of existing market knowledge at all levels.

\section{The benefit of new information}

While new information is acknowledged to be essential for innovation, consistent empirical support is lacking. In considering the limits of market information Sinkula [10] asks: “...when is too much too much?” The conditional effects identified in this study offer a possible answer. New information is only useful when it is effectively integrated with existing knowledge. Our results indicate that disparities in prior work may be due to the lack of consideration of existing knowledge, as the role of new information and existing knowledge can only be understood jointly.

\section{Managerial implications}

Firms need to evaluate existing systems and capabilities before investing in costly new information generation activities. Instead of applying a standard process of information generation to all NPD projects, firms need to adjust their information generation effort according to levels of existing knowledge. This may be achieved by classifying NPD projects based upon their reliance on existing knowledge and developing different information acquisition strategies. Firms may establish procedures of assessing existing systems in the NPD process, which serves as a means to break the inertia of routine information generation. 
The capacity for existing knowledge to impede the effective use of new information raises the issue of mitigation. How can the undesirable effects of existing knowledge be minimized? Physical assets are indicators of existing knowledge but can be replaced to the extent that resources are available. However cultural change within organizations is far more problematic as knowledge associated with values and norms is more difficult to modify. To facilitate learning, firms may set up mechanisms that separate competence from constraining values and norms, and create new incentives that subsume existing hierarchy. For example, relocation of projects away from dominant cultures or instilment of a mentality to challenge authority can help isolate the negative influence of existing knowledge.

Technical knowledge and personnel may be more prone to the negative effects of existing knowledge, and thus greater effort is required to overcome such influences. This is especially the case for technology-driven firms where technical areas play a dominating role in NPD. To overcome the rigidity of existing knowledge, technical functions should be more aware of the need to be open to ideas from other areas [70]. Engineers and scientists may also benefit from developing a broad knowledge base that can provide diverse insights, or working on different projects that offer opportunities for cross-fertilization.

\section{E. Limitations and future research}

While our study is able to identify curvilinear effects of existing knowledge, we are not able to directly measure learning competence and motivation, which would provide further insights on how to leverage competence while preventing the negative motivational effects of existing knowledge. Furthermore, a longitudinal study design would allow more temporal separation and stronger tests of the relationships identified in this study. Our study highlights the complex interaction between new information and existing knowledge, suggesting the need to further understand such complexity. Research that measures information generation and the application of existing knowledge at different NPD stages 
would provide insight into how existing knowledge interacts with new information in specific activities. Because the delivery of services is more dependent upon individual abilities and social interactions [71], new information and existing knowledge are likely to interact to an even greater degree in a service context. Uncertainty in NPD projects and in the external environment is also likely to impact the relationship between new information and existing knowledge, as uncertainty often acts as a catalyst for organizational change yet provokes factions to protect political territories. With a rich variety of research possibilities, we hope that further research finds cause to build upon the framework we have provided for the impact of existing knowledge upon learning in product innovation. 


\section{References:}

[1] G. S. Day, “Closing the marketing capabilities gap,” J. Mark., vol. 75, no. pp.183-195, 2011.

[2] G. R. Heim, D. N. Mallick and X. Peng, "Antecedents and consequences of new product development practices and software tools: an exploratory study," IEEE Transactions on Engineering Management, vol. 59, no. 3, pp. 428, 2012.

[3] S. Thomke, "Enlightened experimentation: The new imperative for innovation," Har. Bus. Rev., vol. 80, no. 4, pp. 74-81, 2001.

[4] J. Frishammar and S. Å Hörte, "Managing external information in manufacturing firms: the impact on innovation performance," J. Prod. Inno. Manage., vol. 22, pp. 251-266, 2005.

[5] L. Berchicci and C. L. Tucci, "There is more to market learning than gathering good information: the role of shared team values in radical product definition," J. Prod. Inno. Manage., vol. 27, pp. 972-990, 2010.

[6] C. Christensen, S. Cook and T. Hall, "Marketing malpractice," Har. Bus. Rev., vol. 12, pp. 74-83, 2005.

[7] A. Grinstein, "The effect of market orientation and its components on innovation consequences: a meta-analysis," J. Acad. Mark. Sci., vol. 36, no. 2, pp. 166-173, 2008.

[8] A. H. Kirca, S. Jayachandran and W.O. Bearden, "Market orientation: a meta-analytic review and assessment of its antecedents and impact on performance," J. of Mark., vol. 69, no.2, pp. 24-41, 2005.

[9] M. Iansiti, "Technology development and integration: An empirical study of the interaction between applied science and product development," IEEE Transactions on Engineering Management, vol. 42, no.3, pp.259, 1995.

[10] J. M. Sinkula, "Market information processing and organizational learning," J. of Mark., vol. 58, no. 1, pp. 35-45, 1994.

[11] GP. Huber, "Organizational learning: the contributing processes and the literatures," Org. Sci., vol. 2, no.1, pp. 88-115, 1991.

[12] W. M. Cohen and D. A. Levinthal, "Absorptive capacity: a new perspective on learning and innovation," Admin. Sci. Qua., vol. 35, no. 1, pp. 128-152, 1990.

[13] D. Leonard-Barton, "Core capabilities and core rigidities: a paradox in managing new product development," Strat. Manage. J., vol. 13 (summer special issue), pp. 111-125, 1992.

[14] B. Levitt and J.G. March, "Organizational learning," Ann. Rev. of Sociology, vol. 14, pp. 319-338, 1988.

[15] N. P. Repenning and J. D. Sterman, “Capability traps and self-confirming attribution 
errors in the dynamics of process improvement. Administrative Science Quarterly, 47(2), 265-295, 2002.

[16] C. Moorman and A.S. Miner, "The impact of organizational memory on new product performance and creativity," J. of Mark. Res., vol. 34, no. 1, pp. 91-106, 1997.

[17] S. Hanvanich, K. Sivakumar and G. T. M Hult, "The relationship of learning and memory with organizational performance: the moderating role of turbulence," J. Acad. Mark. Sci., vol. 34, no. 4, pp. 600-612, 2006.

[18] B. K. Brockman and R. M. Morgan, "The role of existing knowledge in new product innovativeness and performance,” Dec. Sci., vol. 34, no. 2, pp. 385-419, 2003.

[19] M. Song, C. Di Benedetto and M. Parry, "The impact of formal processes for market information acquisition and utilization on the performance of Chinese new ventures," Int. J. of Res. in Mar., vol. 26, no. 4, pp. 314, 2009.

[20] D. R. Chang and H. Cho, "Organizational memory influences new product success," $J$. Bus. Res., vol. 61, no. 3, pp. 13-23, 2008.

[21] S.J. Marsh and G. N. Stock, "Creating dynamic capability: The role of intertemporal integration, knowledge retention, and interpretation," J. Prod. Inno. Manage., vol. 23, pp. 422-436, 2006.

[22] D. H. Henard and D. M. Szymanski, "Why some new products are more successful than others," J. Mark. Res., vol. 38, no. 3, pp. 362-375, 2001.

[23] J. B. Schmidt, K. R. Sarangee and M. M. Montoya, "Exploring new product development project review practices,” J. Prod. Inno. Manage., vol., 26, no. 5, pp. 520-535, 2009.

[24] G. S. Lynn and A. E. Akgun, "Launch your new products/services better, faster." Res. Tech. Manage., vol. 46, no. 3, pp. 21-26, 2003.

[25] L. C. Troy, D.M. Szymanski and P.R. Varadarajan, "Generating new product ideas: An initial investigation of the role of market information and organizational characteristics," $J$. of Acad. of Mark. Sci., vol. 29, no 1, pp. 89-101, 2001.

[26] D.M. Szymanski, S.G. Bharadwaj and P.R. Varadarajan, "An analysis of the market share profitability relationship,” J. of Mar., vol. 57 (July), pp. 1-18, 1993.

[27] R. L. Ackoff, “Management misinformation systems," Manage. Sci., vol. 14, no. 4, pp. 147-156, 1967.

[28] J. M. Sinkula, W.E. Baker and T. Noordewier, “A framework for market-based organizational learning: Linking values, knowledge, and behavior," J. of Acad. of Mark. Sci., vol. 25, no. 4, pp. 305-318, 1997.

[29] L. Fleming, "Recombinant uncertainty in technological search," Manage. Sci., vol. 47, no. 1 , pp. 117-132, 2001. 
[30] L. Fleming and O. Sorenson, "Technology as a complex adaptive system: evidence from patent data," Research Policy, vol. 30, pp. 1019-1039, 2001.

[31] P. E. III Bierly and A. K. Chakrabarti, "Technological learning, strategic flexibility, and new product development in the pharmaceutical industry," IEEE Transactions on Engineering Management, vol. 43, no.4, pp. 368-380, 1996.

[32] B. Kogut and U. Zander, "Knowledge of the firm, combinative capabilities, and the replication of technology," Org. Sci., vol. 3, no. 3, pp. 383-397, 1992.

[33] M. E. Adams, G. S. Day, and D. Dougherty, "Enhancing new product development performance: an organizational learning perspective," J. Prod. Inno. Manage., vol. 15, no. 5, pp. 403-422, 1998.

[34] R. L. Daft and R. H. Lengel, "Organizational information requirements, media richness and structural design," Manage. Sci., vol. 32, no. 5, pp. 554-571, 1986.

[35]. R. M. Baron and D. A. Kenny, "The moderator-mediator variable distinction in social psychological research: conceptual, strategic, and statistical consideration," Journal of Personality and Social Psychology, vol. 51, no. 6, pp. 1173-1182, 1986.

[36] J. P. Walsh and G.R. Ungson, “Organizational memory,” Acad. of Manage. Rev., vol. 16, no. 1 , pp. 57-91, 1991.

[37] V. Govindarajan and C. Trimble, Ten Rules for Strategic Innovators: From Idea to Execution. Boston, MA: Harvard Business School Press, 2005.

[38] A. E. Akgun, G. S. Lynn and C. Yilmaz, "Learning process in new product development teams and effects on product success: a socio-cognitive perspective," Indust. Mark. Manage., vol. 35, pp. 210-224, 2006.

[39] R. G. Cooper and E. J. Kleinschmidt, "Benchmarking the firm's critical success factors in new product development," J. Prod. Inno. Manage., vol. 12, no. 5, pp. 374-391, 1995.

[40] L. M. De Luca and K. Atuahene-Gima, "Market knowledge dimensions and crossfunctional collaboration: examining the different routes to product innovation performance," J. Mark., vol. 71, no. 1, pp. 95-112, 2007.

[41] R. Katila and G. Ahuja, "Something old, something new: a longitudinal study of search behavior and new product introduction," Acad. of Manage. J., vol. 45, no. 6, pp. 1183-1194, 2002.

[42] E. J. Kleinschmidt and R.G. Cooper, "The impact of product innovativeness on performance," J. Prod. Inno. Manage., vol. 8, no. 4, pp. 240-251, 1991.

[43] J. T. Gourville, "Eager sellers and stony buyer: understanding the psychology of newproduct adoption," Harvard Bus. Rev., vol. 84, no.6, pp. 99-106, 2006.

[44] J. S. Armstrong and T. S. Overton, "Estimating non-response bias in mail surveys,” J. 
Mark. Res., vol.14, no. 3, pp. 396-402, 1977.

[45] W. J. Orlikowski, "Knowing in practice: enacting a collective capability in distributed organizing," Org. Sci., vol. 13, no. 3, pp. 249-273, 2002.

[46] R. G. Cooper and E. J. Kleinschmidt, "Determinants of timeliness in product development.” J. Prod. Inno. Manage., vol. 11, no. 5, pp. 381-396, 1994.

[47] E. Danneels and E. J. Kleinschmidt, "Product innovativeness from the firm's perspective: its dimensions and their relation with project selection and performance," J. Prod. Inno. Manage., vol. 18, pp. 357-373, 2001.

[48] R. J. Calantone, J. B. Schmidt and X. M. Song, "Controllable factors of new product success: a cross-national comparison," Mark. Sci., vol. 15, no. 4, pp. 341-358, 1996.

[49] R. G. Cooper, "Stage-gate systems: a new tool for managing new products," Bus. Horizons, vol. 33, no. 3, pp. 44-54, 1990.

[50] A. Ali, R. Krapfel and D. LaBahn, "Product innovativeness and entry strategy: impact on cycle time and break-even time," J. Prod. Inno. Manage., vol. 12, no. 1, pp. 54-69, 1995.

[51] K. Atuahene-Gima, "An exploratory analysis of the impact of market orientation on new product performance: a contingency approach,” J. Prod. Inno. Manage., vol. 12, no. 4, pp.275-294, 1995.

[52] R. P. Bagozzi, Y. Yi and L. W. Philips, "Assessing construct validity in organizational research,” Admin. Sci. Qua., vol. 36, no. 3, pp. 421-458, 1991.

[53] M.K. Lindell and D.J. Whitney, "Accounting for common method variance in crosssectional research designs," J. of App. Psych., vol. 86, no. 1, pp. 114-121, 2001.

[54] P. M. Podsakoff, S.B. MacKenzie, J.Y. Lee and N.P. Podsakoff, "Common method biases in behavioral research: a critical review of the literature and recommended remedies," J. of App. Psych., vol. 88, no. 5, pp. 879-903, 2003.

[55] H. W. Marsh, Z.L. Wen and K.T Hau, "Structural equation models of latent interactions: evaluation of alternative estimation strategies and indicator construction," Psych. Methods, vol. 9, no. 3, pp. 275-300, 2004.

[56] R. Sethi, D. C. Smith and C. W. Park, "Cross-functional product development teams, creativity, and the innovativeness of new consumer products," J. Mark. Res., vol. 38, no. 1, pp. 73-85, 2001.

[57] J. J. P. Jansen, F. A. J. van de Bosch and H. W. Volberda, "Exploratory innovation, exploitive innovation, and performance: effects of organizational antecedents and environmental moderators," Manage. Sci., vol. 52, no.11, pp. 1661-1674, 2006.

[58] T. Li and R.J. Calantone, "The impact of market knowledge competence on new product advantage: conceptualization and empirical examination," J. of Mark., vol. 62, no. 4, pp. 13- 
29, 1998.

[59] E. Yoon and G.L. Lilien, "New industrial product performance: the effect of market characteristics and strategy. The J. Prod. Inno. Manage., vol. 2, no. 3, pp. 134-145, 1985.

[60] V. Shankar, G. S. Carpenter and L. Krishnamurthi, "The advantages of entry in the growth stage of the product life cycle: an empirical analysis," J. Mark. Res., vol. 36, no.2, pp. 269-277, 1999.

[61] L. S. Aiken and S. G. West, Multiple Regression: Testing and Interpreting Interactions. Newbury Park, CA: Sage Publications, 1991.

[62] C. H. Mason and W.D. Perreault, "Collinearity, power, and interpretation of multiple regression analysis,” J. of Mark. Res., vol. 28, no. 3, pp. 268-280, 1991.

[63] M. Song, H. van der Bij and M. Weggeman, "Determinants of the Level of Knowledge Application: A Knowledge-Based and Information-Processing Perspective," J. Prod. Inno. Manage., vol. 22, pp. 430-444, 2005.

[64] K. R. Jespersen, "Stage-to-stage information dependency in the npd process:effective learning or a potential entrapment of NPD gates?" J. Prod. Inno. Manage., vol. 29, no. 2, pp. 257-274, 2012.

[65] G. C. O'Connor, "Market learning and radical innovation: a cross case comparison of eight radical innovation projects," J. Prod. Inno. Manage., vol. 15, pp. 151-166. 1998.

[66] R. R. Nelson and S. Winter. An Evolutionary Theory of Economic Change. Cambridge, MA: Harvard University Press. 1982.

[67] N. Rosenberg. Inside the black box: technology and economics. New York: Cambridge University Press. 1982.

[68] A. W. Ulwick, "Turn customer input into innovation," Harvard Bus. Rev., vol. 80, no. 1, pp. 91-97, 2002.

[69] P. Carbonell-Foulquié, J. L. Munuera-Alemán and A. I. Rodríguez-Escudero, "Criteria employed for go/no-go decisions when developing successful highly innovative products," Indus. Mark. Manage., vol. 33, no.4, pp. 307-316, 2004.

[70] J. P. Workman, "Engineering's interactions with marketing groups in an engineeringdriven organization," IEEE Transactions on Engineering Management, vol. 42, no.2, pp. 129, 1995.

[71] S. L. Vargo and R. F. Lusch, "Evolving to a new dominant logic for marketing," $J$. Mark., vol. 68, no. 1, pp.1-23, 2004. 

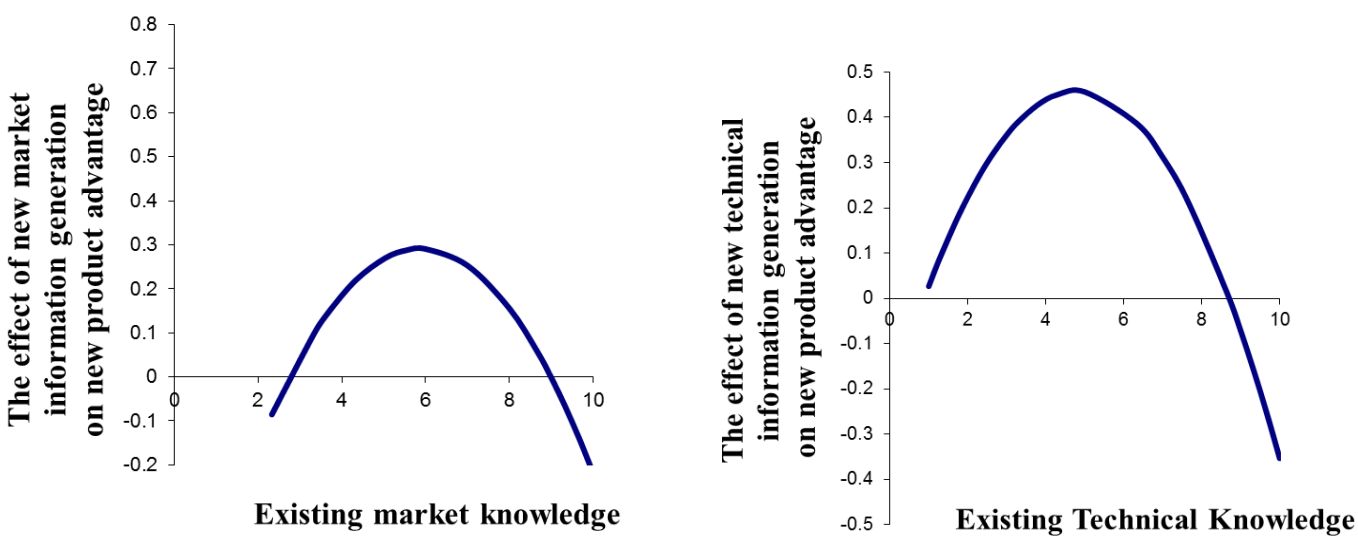

Fig. 1. Curvilinear influence of existing knowledge upon learning
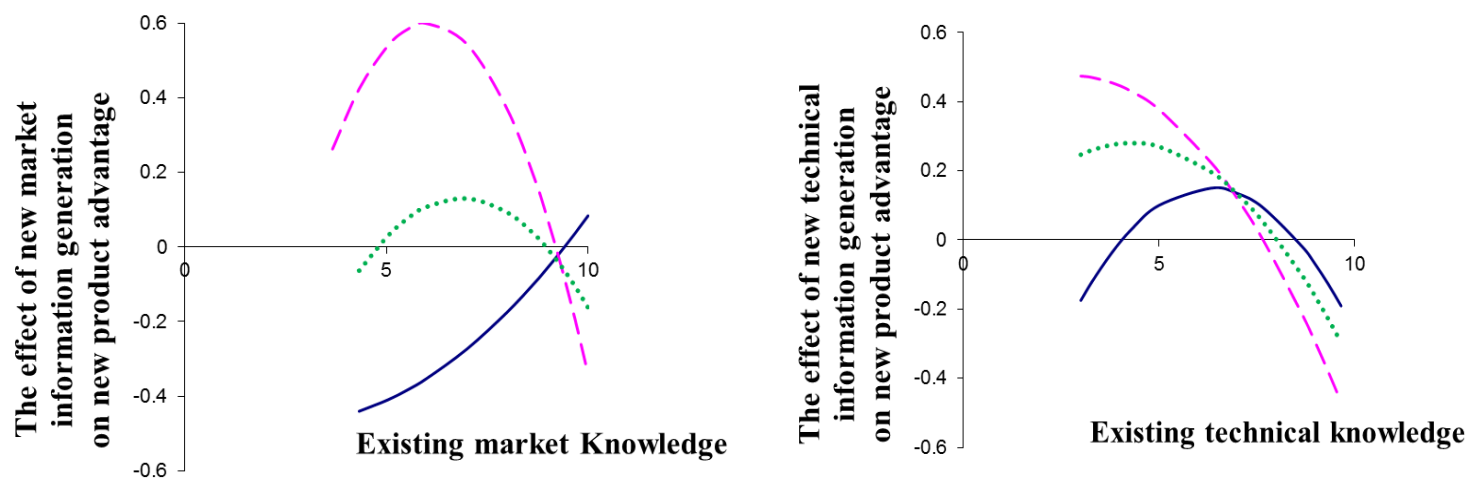

— High Novelty - - Low Novelty $\cdots . .$. Mean Novelty

—High Novelty - - Low Novelty $\cdots . . \cdot$ Mean Novelty

Fig. 2. Curvilinear influence of existing knowledge upon learning under different levels of novelty 
TABLE 1

MEANS, STANDARD DEVIATIONS AND CORRELATIONS

\begin{tabular}{|c|c|c|c|c|c|c|c|c|c|c|c|c|c|c|}
\hline & Mean & $\begin{array}{l}\text { Standard } \\
\text { Deviation }\end{array}$ & 1 & 2 & 3 & 4 & 5 & 6 & 7 & 8 & 9 & 10 & 11 & 12 \\
\hline 1. New market information generation & 5.53 & 1.68 & 1 & & & & & & & & & & & \\
\hline 2. New technical information generation & 7.16 & 1.87 & $0.31^{* *}$ & 1 & & & & & & & & & & \\
\hline 3. Existing market knowledge & 8.04 & 2.15 & 0.05 & $0.19^{* *}$ & 1 & & & & & & & & & \\
\hline 4. Existing technical knowledge & 7.29 & 2.46 & $0.15^{* *}$ & 0.04 & $0.51^{* *}$ & 1 & & & & & & & & \\
\hline 5. Novelty & 6.08 & 2.70 & $0.15^{* *}$ & 0.09 & $-0.20^{* *}$ & $-0.14^{* *}$ & 1 & & & & & & & \\
\hline 6. New product advantage & 6.89 & 1.89 & $0.19^{* *}$ & 0.04 & 0.01 & $0.11^{*}$ & $0.55^{* *}$ & 1 & & & & & & \\
\hline 7. Cross-functional team & 6.77 & 2.31 & $0.34^{* *}$ & $0.41^{* *}$ & $-0.21^{* *}$ & $-0.25^{* *}$ & $0.18^{* *}$ & $0.16^{* *}$ & 1 & & & & & \\
\hline 8. Firm size & 1.31 & 3.79 & $-0.16^{* *}$ & 0.01 & -0.01 & 0.06 & $-0.23^{* *}$ & $-0.28^{* *}$ & $0.11^{*}$ & 1 & & & & \\
\hline 9. R\&D intensity & 3.81 & 2.77 & -0.01 & 0.03 & 0.03 & 0.03 & $0.15^{* *}$ & 0.07 & -0.01 & -0.04 & 1 & & & \\
\hline 10. Order of entry to the market & 1.92 & 1.23 & -0.09 & $0.19^{* *}$ & -0.08 & 0.003 & $-0.35^{* *}$ & $-0.29^{* * *}$ & $0.18^{* *}$ & 0.05 & $0.22^{* *}$ & 1 & & \\
\hline $\begin{array}{l}\text { 11. Stage of product life cycle of } \\
\text { the market }\end{array}$ & 3.60 & 1.33 & $-0.17^{* *}$ & -0.05 & $0.19^{* *}$ & $0.17^{* *}$ & $-0.34^{* *}$ & $-0.21^{* *}$ & $-0.24^{* *}$ & $0.16^{* *}$ & 0.03 & $0.19^{* *}$ & 1 & \\
\hline $\begin{array}{l}\text { 12. Increase of market } \\
\text { competition }\end{array}$ & 6.09 & 1.43 & 0.06 & 0.02 & $-0.11^{*}$ & -0.01 & -0.08 & $-0.17^{* *}$ & $0.16^{* *}$ & -0.07 & 0.03 & 0.002 & 0.07 & 1 \\
\hline
\end{tabular}

1. $* p<0.05, * * p<0.01$

2. Firm size is in thousands of employees. 
TABLE 2.

THE EFFECTS OF NEW INFORMATION GENERATION AND EXISTING KNOWLEDGE UPON NEW PRODUCT ADVANTAGE

\begin{tabular}{|c|c|c|c|c|c|c|c|c|c|}
\hline \multirow[b]{2}{*}{ Variables } & \multirow[b]{2}{*}{ Hs } & \multicolumn{2}{|c|}{ Model 1} & \multicolumn{2}{|c|}{ Model 2} & \multicolumn{2}{|c|}{ Model 3} & \multicolumn{2}{|c|}{ Model 4} \\
\hline & & Coef. & $p$ value & Coef. & $p$ value & Coef. & $p$ value & Coef. & $p$ value \\
\hline Intercept & & 6.89 & $<0.01$ & 6.92 & $<0.01$ & 6.90 & $<0.01$ & 7.13 & $<0.01$ \\
\hline New market information generation & & -0.03 & 0.57 & -0.07 & 0.13 & 0.06 & 0.27 & 0.09 & 0.10 \\
\hline New technical information generation & & -0.08 & 0.06 & -0.11 & 0.01 & 0.09 & 0.09 & 0.10 & 0.08 \\
\hline Existing market knowledge & & -0.01 & 0.84 & 0.03 & 0.43 & -0.04 & 0.45 & -0.11 & $\mathbf{0 . 0 3}$ \\
\hline Existing market knowledge ${ }^{2}$ & & & & & & -0.01 & 0.70 & -0.02 & 0.25 \\
\hline Existing technical knowledge & & 0.20 & $<0.01$ & 0.20 & $<0.01$ & 0.21 & $<0.01$ & 0.12 & $<0.01$ \\
\hline Existing technical knowledge ${ }^{2}$ & & & & & & 0.01 & 0.23 & -0.01 & 0.56 \\
\hline New market information generation $\mathrm{X}$ Existing market knowledge ${ }^{2}$ & H1a & & & & & $-\mathbf{0 . 0 3}$ & $<0.01$ & $-\mathbf{0 . 0 3}$ & $<0.01$ \\
\hline New technical information generation $\mathrm{X}$ Existing technical knowledge & & & & -0.10 & $<0.01$ & -0.16 & $<0.01$ & -0.12 & $<0.01$ \\
\hline New technical information generation $\mathrm{X}$ Existing technical knowledge ${ }^{2}$ & $\mathrm{H} 1 \mathrm{~b}$ & & & & & -0.03 & $<0.01$ & -0.02 & 0.01 \\
\hline Novelty & & 0.29 & $<0.01$ & 0.28 & $<0.01$ & 0.27 & $<0.01$ & 0.21 & $<0.01$ \\
\hline Market information generation X Novelty & & & & & & & & $-\mathbf{0 . 1 0}$ & $<0.01$ \\
\hline Technical information generation $\mathrm{X}$ Novelty & & & & & & & & 0.01 & 0.61 \\
\hline Existing market knowledge $\mathrm{X}$ Novelty & & & & & & & & 0.04 & 0.01 \\
\hline Existing market knowledge ${ }^{2} \mathrm{X}$ Novelty & & & & & & & & 0.01 & 0.06 \\
\hline Existing technical knowledge ${ }^{2} X$ Novelty & & & & & & & & -0.01 & 0.37 \\
\hline Market information generation $\mathrm{X}$ Existing market knowledge $\mathrm{X}$ Novelty & & & & & & & & 0.06 & $<0.01$ \\
\hline Market information generation $\mathrm{X}$ Existing market knowledge ${ }^{2} \mathrm{X}$ Novelty & $\mathrm{H} 2 \mathrm{a}$ & & & & & & & 0.01 & $<0.01$ \\
\hline Technical information generation X Existing technical knowledge $\mathrm{X}$ Novelty & & & & & & & & 0.02 & 0.01 \\
\hline Technical information generation X Existing technical knowledge ${ }^{2} \mathrm{X}$ Novelty & $\mathrm{H} 2 \mathrm{~b}$ & & & & & & & 0.001 & 0.81 \\
\hline \multicolumn{10}{|l|}{ Control variables } \\
\hline Cross-functional team & & 0.24 & $<0.01$ & 0.32 & $<0.01$ & 0.32 & $<0.01$ & 0.24 & $<0.01$ \\
\hline Firm size & & -0.12 & $<0.01$ & -0.12 & $<0.01$ & -0.12 & $<0.01$ & -0.10 & $<0.01$ \\
\hline R\&D intensity & & -0.03 & 0.32 & -0.07 & $<0.01$ & -0.09 & $<0.01$ & 0.01 & 0.72 \\
\hline Order of entry to the market & & -0.29 & $<0.01$ & -0.30 & $<0.01$ & -0.36 & $<0.01$ & -0.27 & $<0.01$ \\
\hline Stage of product life cycle of the market & & 0.07 & 0.24 & 0.10 & 0.06 & 0.12 & $\mathbf{0 . 0 2}$ & 0.22 & $<0.01$ \\
\hline Increase in market competition & & -0.27 & $<0.01$ & -0.32 & $<0.01$ & -0.30 & $<0.01$ & -0.24 & $<0.01$ \\
\hline & & 0.44 & & 0.54 & & 0.57 & & 0.67 & \\
\hline Adjusted $R^{2}$ & & 0.43 & & 0.52 & & 0.56 & & 0.65 & \\
\hline
\end{tabular}

1. Unstandardized regression coefficients are reported. 2. Significant results are in bold font. 3. Firm size is in thousands of employees. 


\section{APPENDIX MEASUREMENT ITEMS}

\footnotetext{
C
}

Constructs

Item-construct

loading

$\lambda$ t-value

New market information generation (11 point scale 0 to 10$) \alpha=0.72$

Rate how well these activities were carried out:

1. Initial screening of the product idea - the first review of the venture

$0.70 \quad 12.91$

2. Preliminary market assessment: An initial, preliminary, but non-scientific market

0.72

13.31

assessment; a first and quick look at the market

3. Detailed market study/market research: marketing research, involving a reasonable

0.64

11.66 sample of respondents, a formal design, and consistent data collection procedure

4. Pre-commercialization business analysis: A financial or business analysis, following product development but prior to full-scale launch*

New technical information generation (11 point scale 0 to 10 ) $\alpha=0.74$

Rate how well these activities were carried out:

1. Preliminary technical assessment: An initial, preliminary appraisal to identify the probable technical route and risks

2. Product development: The actual development of the product resulting in a prototype or sample product

3. In-house product testing: Testing the product in-house; in the lab or under controlled conditions as opposed to in the field or with customers

Existing market knowledge (11 point scale 0 to 10$) \alpha=0.75$

1. To what extent were the competitors that this product took you up against familiar ones ones you had faced before?

2. To what extent was the distribution or channel system that you used for this product familiar or an existing one?

3. To what extent did the type of distribution skills and resources needed for this product fit an existing company distribution system?

4. To what extent were the customer needs served by this product familiar ones - the kinds of needs you have served before*

Existing technical knowledge (11 point scale 0 to 10 ) $\alpha=0.85$

1. To what extent could this product be manufactured using existing company plant and equipment, with no changes required? (0-10 scale)

2. To what extent was the type of product or manufacturing process a familiar or existing one for you?

3. To what extent was the technology used in the development of this product familiar or inhouse technology to you?

4. To what extent did the product involve an inventory versus adaptation of known or existing technology $*$

New product advantage (11 point scale 0 to 10 ) $\alpha=0.82$

1. To what extent was the product superior to competing products in terms of meeting customers' needs?

2. To what extent did the product offer the customer unique attributes or performance characteristics not available from competitive products?

3. To what extent were the benefits offered highly visible ones to the customer... they were very apparent to users?

\section{Novelty}

Rate how innovativeness the product was - its "degree of innovativeness" - relative to products then in your market area. 0 being essentially a copy, a "me-too"; 10 being very innovative, first of its kind. 
Cross-functional team ( 11 point scale 0 to 10 ) $\alpha=0.75$

1. To what extent was the project undertaken by a multi-disciplinary team (e.g. comprised of marketing, R\&D, production, etc.)?

2. To what extent did the team carry the project from beginning to end, i.e., idea to launch?

3. To what extent was the project undertaken by a dedicated team, i.e. they devoted a large percentage of their time to the project?

\section{Firm size}

Number of employees.

\section{R\&D intensity}

Annual R\&D expenditure as a percent of total sales.

\section{Order of entry to the market}

Were you first into the market with this kind of product? Circle only one.
a. $1^{\text {st }}$ in
b. $2^{\text {nd }}$ in
c. $3^{\text {rd }}$ in d. $4^{\text {th }}$ in
e. $5^{\text {th }}$ or later

\section{Stage of product life cycle of the market}

At what stage of the product life cycle was your main market for this product?

(Remember: the product life cycle applies to the whole product group, not just an individual product). Circle only one.

a. Introduction b. early growth c. growth d. early maturity e. mature f. decline

Increase in market competition (reverse coded)

1. To what extent did the aggressiveness of competition and competitive activities increase during this project? $(5=$ no change; 0 being the highest increase, 10 being the highest decrease)

2. To what extent did price competition in the marketplace increase during this project? $(5=$ no change; 0 being the highest increase, 10 being the highest decrease)

\footnotetext{
$*$ These items were dropped during the measurement purification process.
} 


\section{Biosketch}

Anna Shaojie Cui is an Assistant Professor of Marketing at the University of Illinois at Chicago (UIC). Her research interests lie at the junction of product innovation and marketing strategy. She looks at: (1) How firms innovate and the role of marketing in firm innovation; (2) The evolution of business partnerships and its implications for firm innovation.

Kwong Chan is a Visiting Assistant Professor at Northeastern University. His work derives insights from user-generated content to anticipate needs and enhance product innovation.

Roger J. Calantone is Eli Broad Chaired University Professor of Business at The Eli Broad Graduate School of Management at Michigan State University (MSU). He is also adjunct professor of Strategic Management and Economics, and has been recognized as an MSU University Distinguished Faculty. His research is mostly in the areas of product design and development processes, decision support tools for NPD, and organization process metrics.

\section{Photo for Roger Calantone:}

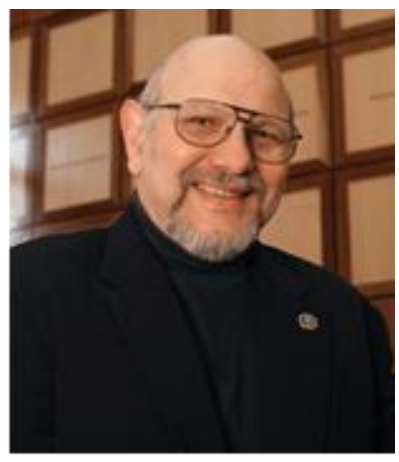

\section{Photo for Anna Cui:}

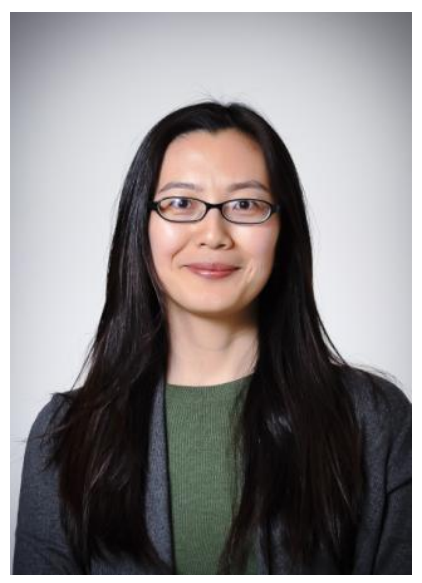

